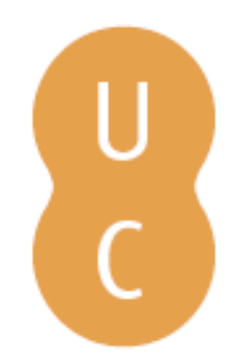

\title{
pommalina
}

\section{Alotropia e desejo de plenitude na modernidade ocidental}

Autor(es): $\quad$ Pereira, José Carlos Seabra

Publicado por: Imprensa da Universidade de Coimbra

URL

persistente: URI:http://hdl.handle.net/10316.2/32075

DOI: $\quad$ DOI:http://dx.doi.org/10.14195/978-989-26-0499-2_24

Accessed : $\quad$ 26-Apr-2023 11:22:10

A navegação consulta e descarregamento dos títulos inseridos nas Bibliotecas Digitais UC Digitalis, UC Pombalina e UC Impactum, pressupõem a aceitação plena e sem reservas dos Termos e Condições de Uso destas Bibliotecas Digitais, disponíveis em https://digitalis.uc.pt/pt-pt/termos.

Conforme exposto nos referidos Termos e Condições de Uso, o descarregamento de títulos de acesso restrito requer uma licença válida de autorização devendo o utilizador aceder ao(s) documento(s) a partir de um endereço de IP da instituição detentora da supramencionada licença.

Ao utilizador é apenas permitido o descarregamento para uso pessoal, pelo que o emprego do(s) título(s) descarregado(s) para outro fim, designadamente comercial, carece de autorização do respetivo autor ou editor da obra.

Na medida em que todas as obras da UC Digitalis se encontram protegidas pelo Código do Direito de Autor e Direitos Conexos e demais legislação aplicável, toda a cópia, parcial ou total, deste documento, nos casos em que é legalmente admitida, deverá conter ou fazer-se acompanhar por este aviso.

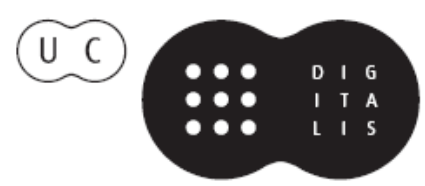


Maria de Fátima Silva

Coordenação

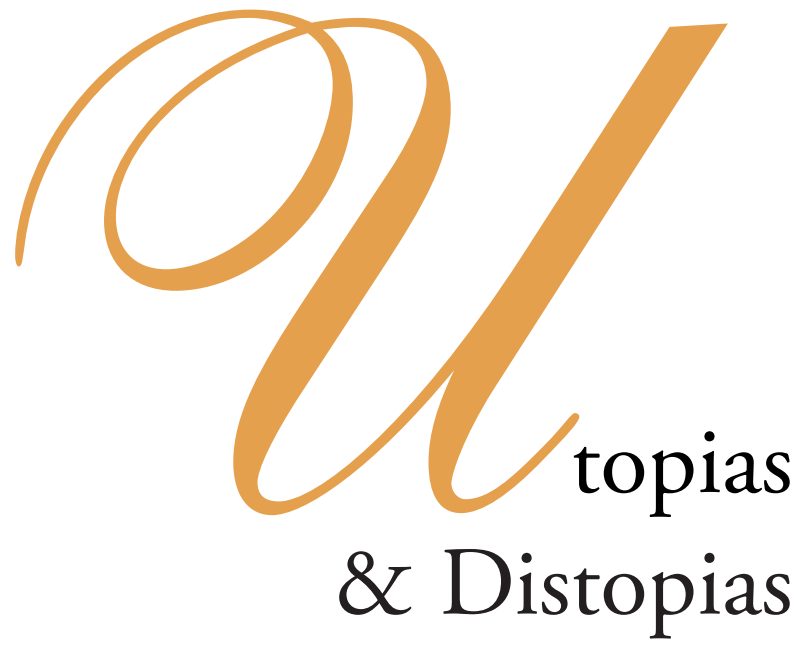




\section{COORDENAÇÃO EDITORIAL \\ Imprensa da Universidade de Coimbra \\ Email: imprensauc@ci.uc.pt \\ URL: http://www.uc.pt/imprensa_uc}

\section{CONCEPÇÃO GRÁFICA}

António Barros

Pré-IMPRESSÃo

Tipografia Lousanense, Lda.

EXECUÇÃO GRÁFICA

Tipografia Lousanense, Lda.

ISBN

978-989-8074-74-4

DEPósito LEGAL

289002/09

OBRA PUBLICADA COM O APOIO DE:

Centro de Estudos Clássicos e Humanísticos

Faculdade de Letras da Universidade de Coimbra

FCT Fundação para a Ciência e a Tecnologia

MINISTÉRIO DA CIÊNCIA, TECNOLOGIA E ENSINO SUPERIOR Portugal 
Maria de Fátima Silva

Coordenação
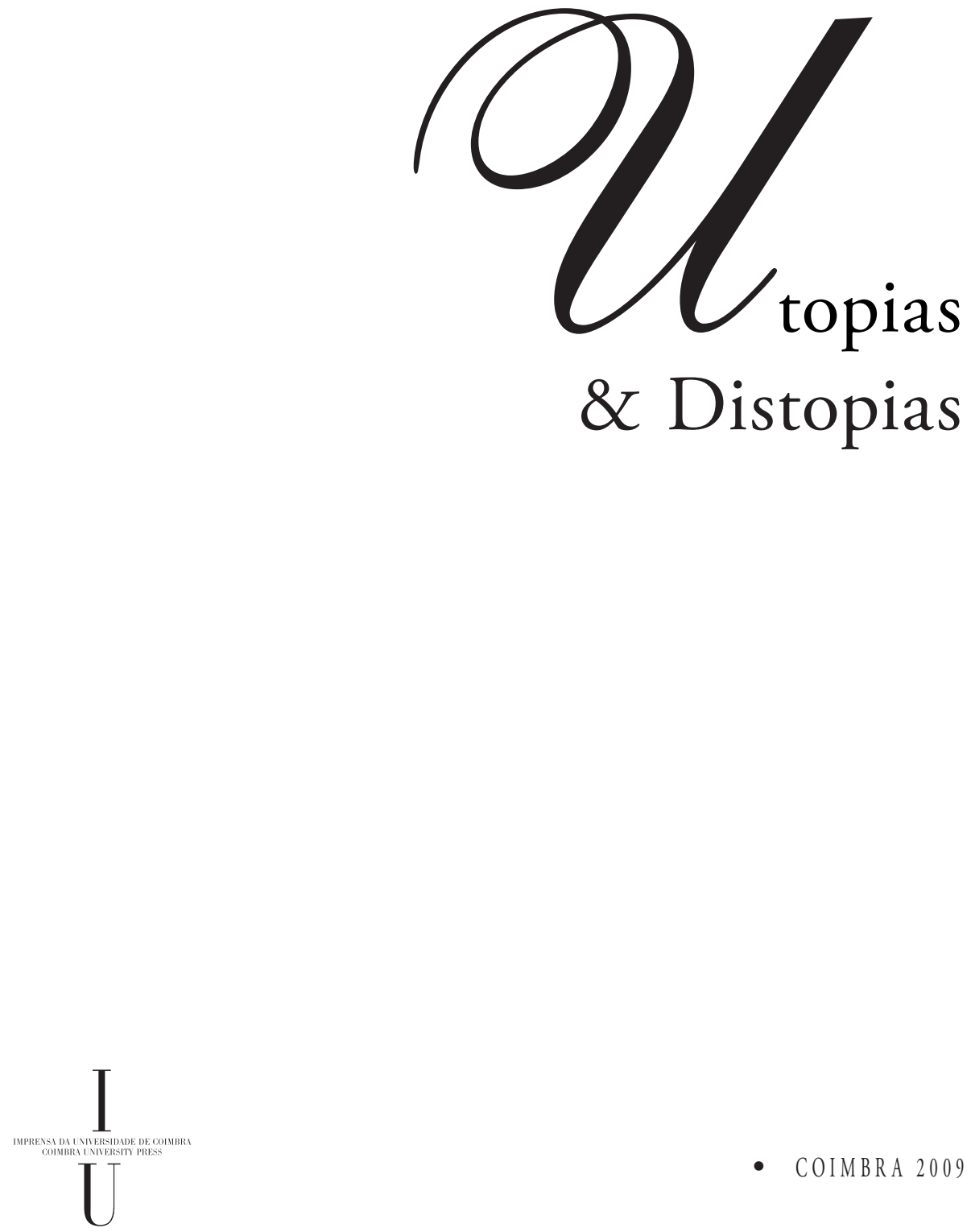

- colmbra 2009 

José Carlos Seabra Pereira

\section{Alotropia E DESEJO DE PLENITUde NA MODERNIDADE OCIDENTAL}

1. Começo por abdicar do preâmbulo camoniano, com que gostaria de tonalizar a dialéctica de consciência de crise e desejo de plenitude, focando no épico e no lírico o desdobramento do desconcerto do mundo (e correspondentes distopias) desde o plano social ao psicológico-moral e deste ao metafísico-religioso, bem como o movimento de repúdio da alienaçáo evasiva "sem mais especular nenhum secreto" e o empenhamento na superação agónica de horizonte escatológico (com a antevisão agustiniana da Jerusalém celeste a transcender as laceraçóes da pastoral maneirista e as eutopias imaginadas do eudemonismo neoplatónico).

Limito-me, pois, a lembrar-vos preliminarmente que o Romantismo marca o advento da modernidade estético-literária euroamericana com o primado da consciência poética (no sentido dilucidado pelo Maurice Blanchot de L'entretien infini), que abre uma bifronte "tradição do novo" (no dizer de Harold Rosenberg) - "tradição de ruptura» e "tradição do heterógeneo" que actua e se cumpre nas frentes da crítica sociocultural e da autocontestação. ${ }^{1}$ Ao mesmo tempo, essa matriz da modernidade estético-literária, definida por Octavio Paz, implica uma lição permanente do Romantismo no plano da antropologia cultural, que, desde os conspectos magistrais de Georges Gusdorf sobre L' Homme Romantique e Le Savoir Romantique, bem como desde o neo-luckacsiano Melancolia e Revolta de Michel Löuvy e Robert Sayre, sabemos consistir numa «má consciência persistente, oposta aos determinismos acabrunhantes da civilização industrial e técnica e da modernidade de massas», e sabemos valer como potencial «objecçáo de consciência, em nome da subjectividade vivida contra os alastramentos invasivos da exterioridade e em nome da imaginaçáo contra a razão mecanicista» ${ }^{2}$.

Por outro lado, a aura com que escritor e discurso românticos se sagram é indissociável do desejo de psicofania e de demiurgia - sob o signo da projecção no eu individual dos atributos transcendentais do Eu absoluto fichtiano (energia pura,

\footnotetext{
${ }^{1}$ Cf. Harold Rosenberg, The Tradition of the New, 2a ed., New York, Mcgraw-Hill, 1965 (ou: ed. brasileira, A Tradição do Novo, São Paulo, Perspectiva, 1974).

${ }^{2}$ Georges Gusdorf, L'Homme Romantique. Paris, Payot, 1984, p. 368.
} 
liberdade irrestrita, potencialidades infinitas), sob o signo da paixão do Belo e do Bem perfeitos (... a demanda da «flor azul» em Novalis e tantos outros) e sob o signo do desejo utópico de plena harmonia com a Natureza e com Deus (à maneira do Hyperion ou o Eremita da Grécia, de Hölderlin, ou por outras vias). Por isso, ensaístas como José Guilherme Merquior enfatizam o valor demarcante do quixotismo romântico do Eu e do Todo, à luz do qual, acrescentamos, se avalia melhor o alcance da sua mitografia da busca do Absoluto. - Fausto, Don Juan -, mas também as suas narrativas mitificantes da errância e do exílio na distopia - Ashaverus, o Judeu Errante, e o Poeta maldito.

Na modernidade subsequente, a história literária da utopia (tão bem estudada pelo pontifex maximus da tematologia, Raymond Trousson, em Voyages ao pays de nulle part) vai prosseguir e enriquecer-se, ganhar novos matizes e contra-figuras. Até porque, pelo seu interior e nas suas margens, com parentescos incônscios ou contrariados, o desejo de plenitude encontrará insuspeitados alótropos - não só em temas e outros macro-signos semântico-pragmáticos (mitos, símbolos arquetípicos, personagens, etc.), mas também em teorias do texto e da comunicação literária ou em novos estatutos da língua literária.

2. Quando, no vértice moderno que supostamente engolfou os modelos e os tópicos da tradição clássica (antiga e renascente), o tema do desconcerto do mundo, anquilosado ou metamórfico parece ser rasurado, nem por isso a literatura deixou de representar disforicamente a detecção e condenação da geografia física e humana que continuava a sonegar a plenitude ansiada - forma impressiva e apelativa de refigurar aquela inconformidade com a (des)ordem reinante que permanece a contraface inalienável das mais altas aspiraçôes do espírito humano, mas também da reivindicação moderna da primazia da subjectividade, do princípio do prazer, da sobreabundância dos bens consumíveis, etc.

Ora, para além das frequentes e extensas realizaçōes temáticas que, subservidas pela descrição e pela narração, a literatura moderna encontra para esse sentido dialéctico da distopia, como negatividade propiciatória da ânsia utópica, entendo que devemos ler a essa luz certos investimentos em programas de géneros e subgéneros literários e também certa transposição para a eficiência sintagmática de outras categorias metatextuais.

Neste último caso estou a pensar no culto romântico e, depois, expressionista do grotesco, que, para além da simbiose inquietante de cómico e sublime, reage à deriva da ironia para o criticismo céptico e à deriva do sarcasmo para o desamor cruel. Por isso, um dos grandes representantes do grotesco que a literatura portuguesa legou à cultura universal da modernidade, Raul Brandão, modulou o leitmotiv de que «nem todo o riso é bom ...", enquanto os seus Gebos e Joanas redimiam o "coração das trevas» pela alotropia da dor e do grito, do sonho e da ternura!

Por outro lado, penso que a fortuna anamórfica da sátira e, em particular, da poesia satírica - distinta e mais plurívoca do que a ficção de tese e a poesia panfletária, preferindo a subversão lúdica ao didactismo ideológico e à crispaçáo sediciosa em favor dos motivos e estilemas de humor disfórico - relança na modernidade a importância sociocultural e antropomórfica que conquistara na Antiguidade, manifestando 
um dos modos mais fecundos de refracção da experiência penosa pelo gozo estético e de indução reversa do ideal de perfeição ético-social nos tempos modernos.

Essa foi já a «segunda compreensão crítica» que Gomes Leal reivindicara, por ser «a mais verdadeira» para a poesia satírica, afinal «obra triste e de desencanto», à contraluz das suas «ideias de paz, de altruísmo, ou do resplandecente e altíssimo verbo da Concórdia - que é o cristalino degrau espiritual da Perfeição.» E em Junqueiro é o desejo do absoluto de uma sátira em chamas que responde à acuidade extrema do sentimento de crise.

Alotropia genológica da catarse do desconcerto do mundo, a poesia satírica justifica, como comprova o recente e amplíssimo estudo universitário, que dela possa nascer «uma dimensão outra de densidade messiânica e ideal, substituta absoluta das ruínas absolutas do passado e do presente» ${ }^{3}$.

Talvez por isso a poesia satírica atinja entre nós, no século XX, uma ímpar virulência verbal e imagística em escritores como José Régio, Tomaz de Figueiredo ou Jorge de Sena, em cuja obra abre caminho para ou margina culminâncias quixotescas, respectivamente, de espiritualidade agónica, nostalgia de illud tempus sem mácula e exigência radical de dignidade imanente do Homem.

Se daqui passássemos às correlaçôes com todas as manifestaçôes hodiernas de carnavalização literária, à luz da conceptualização de M. Bakhtin, achar-nos-íamos com matéria para nova conferência autónoma.

3. Quando não se ergueu, com o Simbolismo, à superação hierática da frustante opacidade fenoménica através da iniciação musical e analógica, o fin-de-siècle pôde - na fronteira fluida entre o Naturalismo, estilo epocal que queria corresponder ao momento eufórico do Cientismo, e o Decadentismo, estilo epocal cuja estesia a um tempo requintada e mórbida queria traduzir a crise de confiança no modelo de Progresso catapultado pela racionalidade científica e pragmática - fazer proliferar as mais chocantes manifestaçôes temático-formais do que poderíamos chamar «distopias antropológicas» assim duplicemente motivadas (desde as patologias hereditárias até à imagística nosológica).

Mas os finais de Oitocentos e os alvores de Novecentos conheceram nova alotropia genológica do fascínio e do terror que geram os ideais de perfeição imanente. Refiro-me às narrativas ficcionais de antecipação que póem o imaginário e os títeres da razão instrumental e do prometeísmo mecânico, do evolucionismo darwinista e da programação cientista, das ideologias igualitárias e colectivistas, ao serviço, nalguns casos, da idealização utópica, mas mais percucientemente ao serviço de nova idealização distópica, visando a denúncia profética dos abismos de danação em que derrocariam tais projectos. H. G. Wells foi pioneiro com A Máquina do Tempo (1895), A Ilha do Dr. Moreau (1896) e A Guerra dos Mundos (1898) - cujo auge de retumbância ficou diferido até à iniciativa mediática de outro Wells genial, o Orson Wells da famosa e aterradora emissão radiofónica de 1938 .

Ora, justamente esse período entre as duas grandes guerras mundiais e o período que se lhe seguiu, atónito perante as utopias e distopias do totalitarismo ideoló-

\footnotetext{
3 Vide Carlos Nogueira, A Sátira na Poesia Portuguesa. Porto, FLUP, 2007.
} 
gico-político e obcecado pelo pavor do cataclismo atómico, vêem recrudescer o romance contra-utópico e também anti-rousseauniano, desde o Nós (1924) de Y. Zamyatin ao Brave New World (1932) de Aldous Huxley, desde o Animal Farm, o Mil Novecentos e Oitenta e Quatro e o Um pouco de ar, por favor! de George Orwell até a $O$ Senhor das Moscas de William Golding.

De facto, marcada no seu limiar (1904) pel' O Coração das Trevas, de Joseph Conrad, a literatura contemporânea tanto promove os grandes engodos pragmáticos da construção de um mundo perfeito e do titanismo mecânico de um Homem Novo já pouco lembrado ou nada afecto à reconfiguração paulina em Cristo Redentor, como reflecte os horrendos desastres e os destroços da ambição totalitária e da suficiência imanentista.

Por isso, ilustra muitas vezes, e bem melhor que o fizera Vicente Blasco Ibañez, novas distopias geradas pelos quatro cavaleiros do Apocalipse; mas, quase outras tantas vezes, ilustra os sonhos e as energias apostados em programas ideológicos de consecução política da perfeição económica e social, se não ética... para de novo ter de reconhecer o desengano e a amargura perante a falência de tão ilusórios ou maléficos projectos.

Náo surpreende, pois, que a literatura novecentista (e as outras artes, em especial o cinema) revisite, assombrada, o tópico das «ruínas» e o reconverta, por vezes, em poética da ruína. Representação pungente da realidade empírica da História e metáfora poderosa da experiência íntima de mundos aluídos, de sistemas de valores pervertidos ou desagregados, a ruína náo está todavia destituída de potencial de relançamento utópico - pelo impulso compensatório e reactivo que germina na própria insustentabilidade do destroço radical; ou náo está de todo desencontrada da vocação de alotropia da demanda de plenitude - pela memória de edificação ascensional que implica e pelo signo de pregnante incompletude em que se constitui.

Por isso, mesmo sob o embate do intelectualismo crítico e do niilismo transcendental, o Modernismo comporta linhas teosóficas de fuga, em ordem à reintegração ontológica; e então o "coração" figura-se como "pórtico partido», com «Deus, a Grande Ogiva ao fim de tudo». ${ }^{4}$

Associada ou náo ao anjo da História de Klee e ao melancólico anjo da alegoria benjaminiana, a poética da ruína tanto legitima distopicamente o protesto contra as inabitáveis condiçôes da circunstância, como se oferece enquanto elemento multissecular da poesia in realia (que a fenomenologia estética, no Jean Cohen de Le haut langage por exemplo, redescobre no refluxo da modelização estruturalista) e torna-se figura de aspiração ad realiora para o homem decepcionado e sedento de Absoluto que, desde o grande Romantismo europeu até ao nosso Raul Brandão, se vê «só, entre ruínas».

Ao longo de todo o século XX, e mormente nos nossos dias, como comprovam as comunicaçôes do recente Encontro de Estudos Portugueses na Universidade de Aveiro, Escrever a Ruina tem sido criativa obsessão dos escritores no Ocidente e em Portugal. E até no seio do nosso Neo-Realismo, um dos mais cultos e sensíveis poetas, João José Cochofel, acusa o síndroma da ruína, entre o remorso ideológico - «Visconti amigo,/ tanto eu como tu nascemos tarde./ Ambos amamos os palácios,/ ambos

\footnotetext{
${ }^{4}$ Fernando Pessoa, «Passos da Cruz - IX, XIV», in Mensagem - Poemas Esotéricos, edição crítica (coord. José Augusto Seabra), 2a ed., Madrid, Archivos, 1996, pp. 129 e 134.
} 
amamos as ruínas/ que o tempo poupou, e as outras/ mais ruínas ainda/ por não querermos nós poupá-las.» - e o anseio de utópica reverdie: «Ruínas. Outono. Nostalgia./ Um agasalho, um ninho/ da futura alegria.» ${ }^{5}$

4. Quando, antes de projectar nas montanhas lusitanas um espaço amoral onde o homo mechanicus poderia converter-se em novo homo misericors, Eça de Queirós encena um dos episódios de $A$ Cidade e as Serras que submetem à reavaliação irónica a pretensiosa barafunda de ismos que encantara as sociedades cosmopolitas em plena apoteose do Cientismo e do Progresso técnico-económico, evoca entáo como «uma tarde, de repente, toda essa massa se precipita com ânsia para o Ruskinismo!»; e Eça faz Jacinto exclamar, em diálogo com Maurício, "Ah, Ruskin! As sete lâmpadas da arquitectura, A Coroa de Oliveira Brava... É o culto da Beleza.» Nesse momento, Eça de Queirós não quer apenas aferir com humor o processo que conduzia ao desalento espiritual de "...Aspiraçôes... Já experimentei... Uma maçada!» ${ }^{6}$; quer também prestar o devido tributo ao fascínio que John Ruskin e a feição utópica da sua sociologia da arte haviam exercido sobre a Europa culta na segunda metade de Oitocentos e de que se ocupara já em "Crónica de Londres» datada de 14 de Abril de 1887.

Com efeito, dotado de faculdades intelectuais e artísticas multifacetadas, John Ruskin (1819-1900) distinguira-se como grande crítico de arte que, na sequência da admiração pela pintura paisagística de Turner e ainda da convergência com os Pré-Rafaelitas, ao mesmo tempo especulou sobre uma Economia política da Arte e apostolou uma religião da Beleza que, implicando culto da arte e culto da natureza, é também uma ética e uma pedagogia sociocultural. Para Ruskin, se a arte é adoração perante a natureza e se a arte é o segredo para revelar Deus na natureza, então há que redimir o Homem moderno educando-o pela arte.

Este ideal de edificação humana pela paideia do imaginário e pela penetração harmónica da arte em todas as fases da vida, formando em simultâneo o gosto e o carácter, cruzou-se no fim-de-século e na viragem para o século XX com outros generosos ideários de perfeição moral e de piedade laica, com neo-evangelismos tolstoianos e sobretudo com a preia-mar de sensibilidade neo-franciscana.

Nesse cosmorama de horizontes utópicos, a versão mais neo-romanticamente religiosa e tradicionalista do ascendente ruskiniano náo deixou de comparecer em Portugal, pela mão de Afonso Lopes Vieira. Mas também não faltou a reacção crítica do emancipalismo vitalista, agitando o labéu da distopia societária e cultural, que persistia incólume perante o equívoco da utopia ruskiniana: «E tanto assim era», redarguia Manuel Laranjeira, «que a teoria de Ruskin foi realizada, sem frutificar: fez-se uma reversão à estilização primitiva: o pré-rafaelismo desfraldou as suas bandeiras; mas as massas continuaram na indiferença de até ali, inertes, inestéticas (...) É por isso que John Ruskin, esse sonhador que será eternamente amado, se enganava quando, numa febre de justiça, num ímpeto de revolta contra a pirâmide esmagadora,

\footnotetext{
5 João José Cochofel, "Visconti amigo», Quatro Andamentos (1964), in Obra Poética. Lisboa, Caminho, 1988, p. 118.

${ }^{6}$ Eça de Queirós, $A$ Cidade e as Serras. Lisboa.
} 
sofrendo do sofrimento dos desgraçados, pedia uma arte para o Povo; o que ele devia reclamar, o grande idealista, era um Povo para a Arte.» ${ }^{7}$

5. Um dos grandes seduzidos pelo magistério de Ruskin foi William Morris, membro relevante de The Pré-Raphaelite Brotherood, desenhista e pintor, contista e poeta, empreendedor bandeirante de Arts \& Crafts, apaixonado pela cultura gótica, editor e tradutor das Odes de Horácio e da Eneida de Virgílio, épico de grandeza homérica (segundo Bernard Shaw) em Sigurd the Volsung (1876) e militante socialista de afinidades marxianas.

Morris planta um marco notável na narrativa utópica com o romance News from Nowhere (1890) que, ao configurar o admirável mundo futuro numa Inglaterra do ano 2012, não só reflecte a estética pré-rafaelita e a medievofilia do autor, mas atesta também a paradoxal pervivência de um imaginário eutópico que era património de uma longa e nobre tradição literária da pastoral, então julgada perdida.

De facto, para contrapor um manifesto ficcional da imaginação política à satirizada distopia da sociedade urbana e industrializada, à miséria da injustiça classista e às convençóes e contradiçóes ético-sociais da era vitoriana, W. Morris representa em «some chapters from a Utopian Romance» o ideal de livre vida comunitária, sem propriedade privada, nem governo, nem sistema penal ou legal, sem sistema institucional de educação formal; e o espaço físico e humano dessa plena harmonia social na vida simples, mas também do trabalho-prazer, da beleza e do deleite erótico, configura-o Morris não consoante as aquisiçôes técnicas e burocráticas da modernidade científico-sociológica e sim numa Londres silvestre, onde as criaçóes humanas (casas e pontes, vestuários e louças, etc.) revestiriam as formas regressivas do próprio cultivo das artes decorativas por Morris e os seus pares.

Revolucionário, portanto, em acepção etimológica, desenvolvendo no movimento do nostos a própria intervenção futurante, William Morris ilustra a remanescente força da pastoral, o poder do imaginário do mito bucólico; e permite assim evocar a persistência (algumas vezes evasiva, outras dolorida e até abjurada) de formas diferentes de nostalgia desse mundo ideal na poesia moderna e contemporânea - apesar das razóes insofismáveis por que Rimbaud proclamou o "fim do idílio» e apesar do acerto de Max Weber ao estabelecer o "desencantamento do mundo» como traço (e ferida) originária da modernidade ocidental.

Pierre Brunel, mestre da literatura comparada, pôde legar-nos um quadro impressionante desse reflexo utópico da consciência infeliz na arte moderna - Arcadie blessée, que afinal reaviva, à sua própria custa e à custa da sua inviável ilusão, uma inquietude já partilhada pelos grandes poetas das épocas clássicas. ${ }^{8}$

Jardim de Armida lacerado, poucos o terão revisitado com tanto fascínio e desenganada lucidez como o poeta italiano Mario Luzi de Un brindisi - aliás, como

\footnotetext{
${ }^{7}$ Manuel Laranjeira, "A Forma em Arte» (1902), in Obras (ed. J. C. Seabra Pereira), vol.II, Porto, Ediçóes ASA, 1993, p. 318.

${ }^{8}$ Pierre Brunel, L'Arcadie blessée - Le monde de l'idylle dans la littérature et les arts de 1870 à nos jours. Mont-de-Marsan, Editions Interuniversitaires, 1996.
} 
"prefiguração semi-orgíaca e semi-alucinada do drama da guerra que destrói o falso Olimpo (...) em que muitos julgavam viver». Travessia exemplar, como argutamente analisou Jean-Yves Masson ${ }^{9}$, que vai ao encontro da ruína contemporânea, mas com um rimbaldiano "dever de demanda", incompatibilizado com a rendiçáo do poeta modernista à armadilha do abandono irresponsável à pureza da magia da linguagem.

6. Outro veio neo-romântico de projecção utópica que emerge na viragem do fim-de-século para o século XX e que margina, quando náo penetra, os terrenos dos Modernismos, é o ambivalente pendor ou sentimento de «desterro da realidade» que, tendo sua dupla vertente disfórica enquanto visão amargurada da realidade circundante e enquanto vivência magoada do exílio, pode todavia defluir para uma vertente eufórica por golpe mágico da imaginação criadora. Lança-se então em busca de uma vivência alternativa, que tire desforço da distopia presente na projecção de uma realidade outra, mercê das energias galvanizantes de mitos sorelianos e paretianos.

A literatura e, em menor escala, outras artes conheceram em Portugal uma extraordinária variante dessa reconversão utópica do «desterro da realidade», quando a imaginação criadora encarregada de a promover se entendeu como imaginação saudosa e pretendeu actuar segundo uma dialéctica mnésico-prospectiva, ao mesmo tempo que, juntando ao telos social de Georges Sorel o ethos nacional de Vilfredo Pareto, assim se assumia como forma mentis e modus operandi do espírito da nacionalidade, isto é, do Volksgeist lusíada.

Lance de palingenesia cultural e de intervenção futurante, este messianismo saudosista irradiou do profetismo doutrinário de Pascoaes e do seu lirismo oracular, mas, em grande parte porque decorria ainda do romântico compromisso da criação estética com a Verdade e com o Mundo, encontrou múltiplas modalidades de sobrevivência, de geração em geração.

Sobremaneira assinalavam essa irradiação os escritores modernos que, como Torga, consideram que «nascemos desterrados, reais ou potenciais, e sempre com parte do sangue no exílio» (e para quem, por conseguinte, "Pascoaes é o trágico aedo existencial dessa nossa condição de eternos exilados da realidade, de encobertos no descoberto, de perseguidores de miragens»). Então, distopia e eutopia irmanam-se conflitualmente na expressão literária do subconsciente individual e colectivo, porque nele lavra «um fogo surdo de amor agónico à pátria, ao mesmo tempo transfigurada em terra eleita e terra perdida» ${ }^{10}$.

Mas, mesmo quando o "horror» da desolação, no descrédito de tudo e no desapego da alma a quaisquer raízes e a qualquer corpo de mátria, se apodera dos protagonistas da aventura literária do século XX, as metamorfoses da Sehnsucht romântica periodicamente se manifestam; e quando, como em Agustina, Os Espaços em Branco de

\footnotetext{
9 Jean-Yves Masson, «Arcadie blessée, Arcadie dévastée: Mario Luzi et le jardin d'Armide», in AA.VV., Le mythe en littérature. Paris, PUF, 2000, pp.343-369.

${ }^{10}$ Miguel Torga, «Teixeira de Pascoaes» (1948), in Fogo Preso, 2aed., Coimbra, 1989/ Ensaios e Discursos, Lisboa, Don Quixote/Círculo de Leitores, 2002, pp.203-204.
} 
O Princípio da Incerteza são também abertura para «saudades pelo que não se alcança e não pelo que se perdeu» ${ }^{11}$, a literatura pós-moderna está sempre permeável à redução existencial daquela «saudade do futuro» que, vinda de Pascoaes, certo F. Pessoa reconvertera - talvez como recurso utópico correlato do que é poventura a forma de distopia mais peculiar do mundo pós-moderno: a errância do viver sem estrutura de horizonte.

7. No processo histórico de coenvolvimento e litígio das modernidades (científico-sociológica e artística), o ciclo do(s) Modernismo(s) - enquanto sistema estilístico- periodológico que, na convizinhança das Vanguardas, mas em confronto com o seu activismo estético, hegemoniza a literatura ocidental nas segunda, terceira e quarta décadas do século XX - vê o princípio pós-baudelairiano de autonomia institucional, axiológica e gnoseológica da arte ser hipotecado ao imperativo de soberania da linguagem e de autotelismo do texto.

$\mathrm{Na}$ «era da suspeita», que é contexto de crise epistemológica sob o signo da teoria da relatividade, do princípio da incerteza, do descentramento do eu e da crise protoexistencialista da consciência infeliz e do assédio do absurdo, a literatura move-se segundo a dupla teleologia pessoana de «interpretar e opor-se à realidade sua coeva» e de «aumentar a autoconsciência humana»; mas autolimita-se na pragmática imanentista do texto (ou da linguagem em texto).

$\mathrm{Na}$ verdade, porém, a figuração de distopia defluente da relação do sujeito com a História e com o mundo empírico da sua circunstância não se deixa rasurar na odisseia da Consciência no texto modernista - até porque, segundo Blumemberg, o Modernismo recria a mitografia deceptiva contra o «absolutismo da realidade» e sob a angústia da descrença no controlo dos meios de existência. E a proscrita demanda de plenitude transcendente ao texto introjecta-se, afinal, na utopia da forma perfeita e da palavra total, enquanto o horizonte intemporal dessa plenitude utópica se transpóe para um ersatz que encontrará excelente fortuna até à literatura pós-moderna dos nossos dias.

Neste último caso, refiro-me à perseguição da apoteose existencial do instante: coonestado ou náo pela genealogia prestigiosa do carpe diem, as criaçóes literárias do Modernismo, do Neo-Modernismo e do Pós-Modernismo investem inconfessado desejo de absoluto na epifania ocasional ou na conquista fungível de um sucedâneo de plenitude na contingência do momento (tópico entre nós dilucidado por Rosa Maria Martelo e outros ensaístas).

Mas o Modernismo legou também outro vector que denuncia a falta que fica a ressentir-se no processo de orteguiana «desumanização da arte» pela primazia da pessoana "emoção estrangeira», isto é, alienada em sede de restrita existência textual. Esse vector determina que, perto do fim, Álvaro de Campos sagre a aventura modernista náo só com a nostalgia da "virtude do desenvolvimento rítmico/ Em que a ideia e a forma,/ Numa unidade de corpo e alma,/ Unanimemente se moviam ...", mas ainda e sobretudo com esta nostalgia de uma «ode» (de uma obra) outra:

${ }^{11}$ Agustina Bessa-Luís, O Principio da Incerteza - III - Os Espaços em Branco. Lisboa, Guimarães Editores, 2003, p. 242. 
E aquela, a última, a suprema, a impossível!

Esse vector é que determina que, no seio do Segundo Modernismo presencista, a lírica de Saúl Dias tenha, no termo do seu Vislumbre, um rasgo de exigência contrastante com o low profile da sua trajectória:

A vida inteira para dizer uma palavra!

Felizes os que chegam a dizer uma palavra!

Esse mesmo vector é que determina que, mais tarde, o romance problemático e lírico de Vergílio Ferreira tonalize, com a revalorização epigráfica daqueles versos de Saúl Dias, a obsessiva demanda da "palavra que conhece o mistério e que o mistério conhece», a «última», a "primeira» ....12

${ }^{12}$ Fernando Pessoa, Poemas de Álvaro de Campos, ed. crítica (Cleonice Berardinelli), Lisboa, INCM, 1990, pp. 251-252; Saúl Dias, Obra Poética, 2aed, Porto, Brasília Editora, 1980, p. 269; Vergílio Ferreira, Para Sempre, Lisboa, Bertrand, 1983, pp. 7 e 306, e passim. 


\section{Série}

\section{Documentos}

Imprensa da Universidade de Coimbra

Coimbra University Press

2009

- $\mathrm{U}$

C • 